\title{
Identidades Negociadas, Autenticidades Redefinidas: Políticas do patrimônio e turismo cultural entre os Rabelados de Cabo Verde
}

Rodrigo Marques Leistner ${ }^{\mathrm{a}}$

Os Rabelados configuram comunidades rurais originárias da resistência ao poder colonial em Cabo Verde, as quais se desenvolveram parcialmente isoladas do Estado desde os anos 1940. Recentemente, no entanto, iniciativas empreendidas por mediadores culturais objetivam a inserção desses coletivos junto à sociedade envolvente, e nesses propósitos, as políticas de patrimonialização e o turismo cultural se apresentam como principais instrumentos. Partindo-se dessas realidades, o artigo aborda as complexidades que envolvem os agenciamentos referidos. Por um lado, busca-se caracterizar as formas pelas quais os agenciamentos em torno da cultura se tornaram centrais na contemporaneidade; por outra via, avalia-se os resultados mais aparentes desses empreendimentos para o caso dos Rabelados, com especial atenção em relação às problemáticas das negociações identitárias e da autenticidade.

Políticas de patrimonialização, Turismo cultural, Identidades, Autenticidades.

Ao desembarcar pela primeira vez na ilha de Santiago para ministrar um curso na Universidade de Cabo Verde, meus objetivos como antropólogo visavam aproximar a prática docente de atividades de pesquisa. Afinal de contas, antropólogos quase sempre se encontram

a Doutor em Ciências Sociais (UNISINOS). Professor Adjunto da Área de Sociologia da Universidade Federal do Rio Grande (FURG). Email: rodrigoless@ yahoo.com.br. 
numa busca entusiasmada pela delimitação de campos etnográficos propícios para desenvolver a crítica da alteridade; e não raramente, os contatos com a cultura de um País distante reforçam essa perspectiva. Esse quadro de expectativas se ampliava na medida em que as realidades encontradas em cidades como Praia, Ribeira Grande e Mindelo sinalizavam um terreno fértil para análises comparativas em relação a um projeto de pesquisa sobre políticas culturais em fase de desenvolvimento no Brasil ${ }^{1}$. A fecundidade mencionada relacionava-se com a larga dimensão que os agenciamentos em torno da concepção de cultura adquirem atualmente em Cabo Verde: processos de patrimonialização, indústrias criativas e ativismo cultural eram tópicos recorrentes no contexto em que eu acabava de aportar. De posse desse horizonte e em contato com outras tantas expressões culturais do arquipélago, detectei junto aos coletivos denominados Rabelados um instigante contexto para incursões investigativas, as quais passaram a integrar uma agenda de pesquisa mais ampla sobre os agenciamentos da cultura na sociedade cabo-verdiana contemporânea²

Concebidos como movimento religioso símbolo da resistência ao colonialismo (Ascher 2011), os Rabelados constituem coletividades distribuídas de modo disperso pela ilha de Santiago, estruturadas com base num catolicismo popular amplamente disseminado nas zonas rurais. Historicamente, constata-se o desenvolvimento de identidades coletivas definidas em franca oposição às deliberações do catolicismo oficial e do Estado colonial (Monteiro 1974). Destaque-se ainda que as relações tensas travadas com essas estruturas de poder redundaram não apenas em ações repressivas direcionadas ao grupo, mas também numa estratégia de autoisolamento a partir da qual tais coletivos permaneceram relativamente apartados do Estado e da sociedade mais ampla por seis décadas. Recentemente, entretanto, tal separação tem se alterado decisivamente, e os Rabelados vivenciam um efetivo processo de 'abertura' em relação aos contextos externos. Essa tendência tem se efetuado a partir da mediação de ativistas culturais que propõem a reconexão do grupo com a sociedade envolvente. Assim, ampliam-se 
os projetos que visam o acesso a bens e serviços públicos ligados à saúde e educação, até então distantes daquelas comunidades, e como demonstra Gonçalves (2009), tal processo tem gerado conflitos internos e profundas alterações na identidade rabelada.

De fato, considerações relativas à historicidade e às experiências contemporâneas desses grupos sugerem questionamentos investigativos estimulantes. Por um lado, os processos de ação política ancorados na experiência religiosa já foram devidamente avaliados como propícios para se pensar a dinâmica social, observando-se um campo privilegiado de estudos sobre os modos pelos quais diferentes sistemas simbólicos permitem a emergência de linguagens de contestação (Balandier 1976). Por outra via, as complexidades que envolvem a aproximação de comunidades rurais com lógicas externas às suas estruturas de reprodução têm se demonstrado favoráveis para reflexões sobre os diferentes arranjos através dos quais esses coletivos negociam sua aproximação com os signos da modernidade e com o sistema capitalista (Canclini 2013).

No entanto, em minhas aproximações iniciais com os Rabelados detectei realidades ainda mais intrigantes, cujos contornos evidenciavam uma terceira possibilidade de reflexão. Ao chegar à aldeia dos Rabelados do Espinho Branco ${ }^{3}$, deparei-me com uma paisagem etnográfica sintomática: turistas, vindos de diferentes países, desfrutavam do contato direto com o cotidiano da aldeia, alternando suas atividades entre o consumo do artesanato local, as fotografias tiradas com os 'nativos' e uma contemplação atenciosa das narrativas de uma ativista ligada à comunidade; jornalistas europeus circulavam pelo espaço coletando informações sobre a histórica resistência ao Estado colonial, bem como sobre os atuais projetos educativos e sociais que envolvem a aldeia; por sua vez, antropólogos (eu, inclusive) ouviam atentamente os discursos êmicos, que não apenas recuperavam aspectos básicos da religiosidade dos Rabelados como ainda salientavam a importância de considerar sua cultura como um patrimônio da sociedade cabo-verdiana. Em síntese, em minha primeira visita à comunidade do Espinho Branco, tornava-se clara a noção de que a vida da aldeia não apenas 
passava por transformações complexas decorrentes da recente abertura em relação à sociedade envolvente, mas, sobretudo, organizava-se prioritariamente em torno de determinados agenciamentos culturais, especialmente aqueles que se relacionam com os empreendimentos de patrimonialização e turismo cultural.

Com base nesses fatores, meus interesses etnográficos se orientaram para os possíveis sentidos daqueles agenciamentos, e é justamente em torno dessa problemática que o texto aqui apresentado se desenvolve. Proponho refletir sobre os significados que concernem à emergência das políticas de patrimonialização e implementação do turismo cultural entre os Rabelados de Cabo Verde, tomando como foco da análise as realidades disponíveis atualmente na comunidade do Espinho Branco ${ }^{4}$. Desenvolvo a reflexão a partir de duas frentes: por um lado, caracterizo as formas básicas pelas quais os agenciamentos em torno da cultura se tornaram centrais na contemporaneidade, aqui incluindo-se a relação entre turismo e patrimônio; por outro, reflito sobre os resultados mais aparentes desses processos para o caso dos Rabelados, com especial atenção às problemáticas das negociações identitárias e da autenticidade 5 .

Nesse último aspecto, em acordo com algumas análises disponíveis sobre tópicos contíguos (Cf. Comaroff \& Comaroff 2009; Azarya 2004; Daniel 1996; Boniface \& Fowler 1993; Canclini 1983), considera-se que as temáticas da identidade e autenticidade se apresentam como chaves interpretativas centrais para avaliações sobre os impactos de determinados agenciamentos culturais em comunidades rurais e periféricas, sobretudo aqueles que se estabelecem a partir das tecnologias patrimoniais e da implantação do turismo de baixa escala (cultural, rural, ecológico, etc.). Não significa que tais categorias esgotem as possibilidades de análise sobre os custos implicados naqueles empreendimentos. O que se está propondo é que categorias como identidade e autenticidade demonstram-se com potencial heurístico para o desenvolvimento de sínteses analíticas que abarquem os principais tensionamentos presentes nos agenciamentos colocados sob observação ${ }^{6}$. 


\section{As comunidades rabeladas: da contestação religiosa à abertura em relação à sociedade global}

A estruturação dos grupos Rabelados encontra-se ligada à constituição de uma matriz identitária de contornos mais ou menos aparentes, cujos sentidos se ligam a experiências religiosas articuladas num contexto rural e a processos de identificação sedimentados em diversas contendas travadas com as estruturas do poder colonial. Esses tensionamentos são insinuados nas próprias negociações semânticas que envolvem uma denominação genérica: o termo Rabelados, contração linguística do crioulo cabo-verdiano para rebelados, corresponde tanto à acusação de rebeldia aplicada aos sujeitos que historicamente resistiram às determinações da Igreja e do Estado quanto a uma ressignificação semântica acionada por aqueles mesmos sujeitos, vítimas da acusação: na perspectiva do grupo, o termo Rabelado faz referência à ideia de 'revelação', possibilidade de manifestação e acesso a um cosmos sagrado, numa exegese em que o uso sinonímico de rebeldia e revelação possibilita a conversão simbólica de rebeldes em 'escolhidos de Jesus Cristo'.

Segundo Monteiro (1974), essas negociações da realidade partem de circunstâncias que remontam à década de 1940, sendo necessário avaliar o contexto do catolicismo praticado em Cabo Verde no início do século XX. Como propõe esse autor, um processo de deterioração das estruturas de reprodução do catolicismo oficial combinou-se com um modelo de ocupação territorial no qual amplos contingentes populacionais ficaram apartados dos núcleos políticos e administrativos fixados em cidades como Praia. Essa condição favoreceu a disseminação de experiências religiosas singulares que se constituíram como principal fonte de identidade para os sujeitos das zonas rurais e de difícil acesso da Ilha de Santiago. Por um lado, o desmantelamento da empresa religiosa oficial decorreu da precária formação de sacerdotes locais e da escassez de recursos destinados aos trabalhos de evangelização; por outro, e com base nesse processo de desagregação, observou-se a emergência de práticas e sistemas de representação distantes de uma ortodoxia 
de Igreja, caso dos rituais extáticos, da ausência de mediação sacerdotal ou das exegeses particulares sobre as escrituras sagradas. Trata-se de um contexto em que foram geradas condições favoráveis para o desenvolvimento de formas típicas da religiosidade popular (Martín 2009), cujos aspectos demonstraram-se compatíveis com as demandas religiosas das coletividades rurais espalhadas pela ilha de Santiago.

Se os fatores ligados a esse modelo de organização do catolicismo cabo-verdiano favoreceram a emergência de sistemas religiosos típicos, a configuração de uma identidade propriamente rabelada só foi possível devido a determinadas conjunturas políticas do primeiro quartel do século XX. Tal contexto relaciona-se com a emergência de processos de resistência dos países africanos em relação às políticas colonialistas, em circunstâncias que não raramente demandaram dos Estados imperiais uma reaproximação com a Igreja no intuito de assegurar a dominação das colônias. Como demonstra Ascher (2001), foram esses os traços fundamentais que motivaram a reconciliação entre o Estado Novo de Salazar e o catolicismo português, e foi com base nessa perspectiva que, em 1941, aportaram em Cabo Verde os sacerdotes da Congregação do Espírito Santo, que iniciaram processos ativos de reordenamento doutrinário e ritual do catolicismo local.

Diante desses processos, duas tendências se consolidaram: por um lado, a resistência de parte da população que não apenas refutou a autoridade missionária em serviço nas diversas freguesias da Ilha de Santiago, mas ainda conservou práticas religiosas nos moldes do que lhes fora transmitido pelos antigos padres da região - os padres 'da terra' ou de 'batina preta' (Cf. Monteiro 1974); por outra via, observou-se um acionamento instrumental da administração colonial por parte dos novos representantes da Igreja, os quais visaram subjugar os sujeitos que resistiam àquelas missões. Fora desse modo que, num primeiro momento, os resistentes passaram a ser categorizados como 'descrentes' (Cf. Ascher 2011).

Contudo, uma definição mais aparente das fronteiras que articulam a identidade dos Rabelados se efetuou apenas em 1961, numa 
ocasião em que se combinaram uma missão de estudo e combate a endemias (cujos trabalhos incluíam propósitos de erradicação da malária através da pulverização de residências e vacinação) com um projeto de demarcação de propriedades rústicas determinado pelo Governo local. Como descreve Monteiro (1974), diversos indivíduos de diferentes regiões da ilha de Santiago se recusaram a colaborar com a missão, impedindo a entrada nas residências ou negando a participação nos procedimentos de vacinação. Como refere esse autor, o ponto em comum entre os agentes em resistência consistia no fato de que todos se enquadravam na categoria dos descrentes, ou seja, aqueles que outrora recusaram a autoridade dos novos missionários. Assim, ampliavam-se as percepções coletivas sobre a existência de um movimento religioso de características rebeldes, consolidando-se as representações oficiais sobre os 'Rabelados da Ilha de Santiago'.

As formas pelas quais se desenvolveram essas definições semânticas se demonstram importantes, verificando-se negociações de realidade que não apenas partiram das identificações externas projetadas sobre o grupo, mas ainda da constituição de pertenças coletivas que se reforçaram, em termos endógenos, a partir daquelas próprias definições exteriores. No âmbito das representações e práticas articuladas pelos agentes externos é possível constatar um extenso repertório de atitudes repressivas, em parte sustentadas pelo discurso do catolicismo oficial (baseado em oposições como civilização/ barbárie) ${ }^{7}$, em parte pela ação estatal (vide as prisões e deportações dos rebeldes para outras ilhas do arquipélago). O próprio estudo de Júlio Monteiro configura exemplo assertivo das iniciativas de controle empreendidas pelo Estado cabo-verdiano, tendo sido encomendado na década de 1960 visando afastar a hipótese de que a 'seita' dos Rabelados comportasse qualquer projeto político anticolonialista ${ }^{8}$.

Ainda assim, como a própria investigação de Monteiro sugeriu, a configuração de uma pertença Rabelada esteve muito mais relacionada à constituição de um espaço de ação autônoma segundo as fronteiras que os próprios coletivos criaram em relação à sociedade envolvente. 
Aqui se torna possível considerar as formas embrionárias pelas quais a identidade do movimento dos Rabelados se constituiu: uma oposição à sociedade envolvente, concebida como espelho da repressão sofrida e foco de uma ação profana. Nesse caso, percebe-se a existência de mecanismos discursivos que operam através da oposição entre espaços profanos (sociedade mais ampla) e sacralizados (as comunidades Rabeladas), uma esfera de relações endógenas sendo concebida como único campo de ação possível e distante das determinações do poder instituído.

Como propôs Gonçalves, tal estratégia se constituiu como uma espécie de "alternativa à sociedade dominante" (2009:239), tendo sido empreendida através ações modelares, como a recusa na adoção de documentos de identificação por parte dos Rabelados. Embora a ideia de um isolamento efetivo jamais tenha se concretizado (Monteiro 1974), é somente na década de 1990 que uma abertura mais efetiva em relação ao Estado e à sociedade mais ampla se consolida, e nesse sentido, a atuação dos mediadores culturais se apresentou como decisiva.

Esse é o caso dos processos ocorridos na comunidade do Espinho Branco, sobretudo através da chegada à região da artista plástica, poetisa e ativista cultural cabo-verdiana Maria Isabel Alves. Conhecida como Misá, sua trajetória inclui a circulação intensa pelos circuitos artísticos estabelecidos entre o continente africano e europeu, além de contatos assíduos com representantes de agências nacionais e internacionais de fomento à cultura e desenvolvimento. Após anos residindo em países como Suíça e Costa do Marfim, Misá retorna para a terra natal visando desenvolver projetos de intercâmbio cultural entre agentes sociais ligados a contextos rurais e urbanos, através de oficinas artísticas que, segundo sua expectativa, teriam o potencial de gerar processos de reconhecimento e valorização das especificidades culturais de Cabo Verde.

Com base nesses propósitos, Misá concebe junto aos Rabelados um contexto relevante para empreender seus projetos. Após ser aceita 
pela comunidade mediante uma longa negociação com os chefes do coletivo do Espinho Branco, iniciam-se os agenciamentos e as parcerias com instituições públicas ou privadas visando à obtenção de recursos destinados à saúde e educação, assim sendo viabilizadas as consultas médicas e o acesso de crianças à rede pública de ensino?. Em paralelo a essas ações, Misá introduziu as artes plásticas na comunidade, formando um grupo de artistas Rabelados que mantém uma produção constante em peças de pintura e artesanato. As obras são comercializadas na própria comunidade ou em noutros pontos turísticos da ilha de Santiago, o que gera parte dos recursos alocados nos projetos sob desenvolvimento na aldeia. Em geral, esses projetos são definidos e empreendidos através da Associação dos Rabelados de Santiago (Rabelarte), fundada em 1998.

Segundo Gonçalves (2009), logicamente, esses empreendimentos têm acelerado o movimento de abertura da comunidade em relação à sociedade global. Atualmente é possível apreciar um contexto no qual os agentes anteriormente 'isolados' estabelecem laços com a modernidade de diferentes modos, seja através do contato com as novas tecnologias (os Rabelados possuem celulares e mantém perfis públicos em redes sociais do tipo Facebook), seja através da ampliação das redes de sociabilidade geradas pelos projetos de inserção social (os membros da comunidade viajam à Europa para expor suas peças em galerias de arte). Como propõe essa autora, tal contexto suscita dúvidas sobre os impactos que essas ações geram para os próprios coletivos. Contudo, antes de avaliar os possíveis custos do processo, torna-se relevante observar as principais estratégias através das quais esses empreendimentos têm sido realizados. Conforme já referido, essas modalidades de ação têm sido colocadas em prática a partir de concepções mais ou menos estáveis nas quais a cultura é percebida prioritariamente como um recurso. No caso dos Rabelados, tal recursividade é acionada através dos discursos de patrimonialização e das iniciativas de implantação do turismo cultural, fatores que se tornam visíveis no cotidiano da aldeia do Espinho Branco. 


\section{Um tour pelos Rabelados: impressões etnográficas sobre agenciamentos da cultura}

Avaliar que os discursos do patrimônio e os empreendimentos de turismo cultural correspondem a elementos centrais nos agenciamentos que envolvem os Rabelados não significa propor que os mesmos compreendam empreendimentos de vulto gerenciados por corporações internacionais ou pela ação estatal, como ocorre em determinados projetos atualmente desenvolvidos em Cabo Verde (Santos 2009). No caso dos Rabelados, embora o contato com o campo institucional não seja raro, percebe-se uma configuração em que tais iniciativas operam muito mais no âmbito de ações estratégicas elaboradas pela própria comunidade. Dito de outro modo, observamse agenciamentos que se encontram num nível propositivo e cujas perspectivas têm sido delineadas nas recentes relações estabelecidas com os mediadores culturais. Assim, o contexto aqui enfocado relaciona-se com algumas modalidades de ação nas quais o patrimônio e o turismo se inserem na agenda de atores rurais/ periféricos, os quais reivindicam o reconhecimento de suas especificidades identitárias e estabelecem táticas de apropriação de recursos baseadas na comercialização de seus artefatos culturais.

A relação entre esses agenciamentos e a ideia de patrimônio pode ser avaliada a partir dos aspectos discursivos que concernem às noções de patrimonialização acionadas nos empreendimentos da aldeia, aqui se considerando os elementos culturais selecionados como objetos de possivel salvaguarda e os argumentos de sua justificação. Através de uma articulação meticulosa entre a caracterização dos objetos alvo do patrimônio e a reiteração de suas especificidades, tais discursos enfatizam a noção de que os Rabelados representariam a memória viva das formas de organização social tradicionais de Cabo Verde, especialmente em suas características rurais. Além disso, tratar-se-ia de um grupo portador de uma cosmovisão muito particular, cujos aspectos principais correspondem aos sistemas de troca baseados na reciprocidade (a lógica do djunta mon), aos arranjos familiares característicos 
(que incluem o casamento poligâmico) e aos processos de resolução de conflitos mediados pela religiosidade. É com base na detecção do avanço da modernidade hegemônica e dos perigos que esse movimento representa para a continuidade daquela visão de mundo que se estabelecem as justificativas para as propostas de preservação.

Se os aspectos acima referidos relacionam-se ao conteúdo dos discursos patrimoniais, também é necessário avaliar o modo como esses discursos são empregados, em termos recursivos. Nessa perspectiva, verifica-se que o acionamento da categoria patrimônio constitui o cerne das agendas reivindicativas dos Rabelados, seja no caso de demandas políticas (reconhecimento, representatividade e inserção social), seja no agenciamento de expedientes econômicos. Como exemplo pode ser relatada a presença constante dessa categoria nos projetos de captação de recursos elaborados pela Associação Rabelarte e enviados a agências e instituições privadas e governamentais. Nesses documentos, são invariáveis as referências sobre a importância da valorização do patrimônio de comunidades como a do Espinho Branco (seja para a autoestima de seus membros, seja para reorientar as representações negativas de que foram vítimas), além de serem ressaltadas as relações de interdependência entre a preservação do patrimônio cultural e o incremento econômico para os membros da comunidade - nesse último caso sendo considerados os vínculos entre as tecnologias patrimoniais e os projetos de geração de renda ancorados na exploração do turismo cultural.

É justamente nesse ponto que os discursos relativos ao patrimônio se conectam aos empreendimentos turísticos, através de combinações que se tornam eixos capitais dos agenciamentos colocados em prática. Trata-se de um modelo de relação em que as tecnologias patrimoniais instituem atrativos para a mobilização turística na mesma medida em que o turismo gera recursos para a implantação dos projetos de patrimonialização (Dias 2006), numa articulação definida como sustentável. Daí a centralidade desses empreendimentos em contextos de demandas por reconhecimento identitário e geração de recursos 
para comunidades rurais ou periféricas, cujas carências poderiam ser atendidas tanto pelos discursos de valorização do patrimônio (reconhecimento) quanto pelas atividades turísticas (geração de recursos), reiterando-se, nesses casos, o potencial de viabilidade dos projetos.

No âmbito dos Rabelados, é exemplo dessas perspectivas a própria configuração material e espacial da aldeia do Espinho Branco. Em processo de construção desde a década de 1990, a aldeia abrigou famílias que anteriormente se distribuíam de modo disperso pela região, tendo sido projetada para conter residências edificadas no padrão construtivo tradicional das comunidades rabeladas - caso dos funcos (ou 'presépio'), construções simples de palha e madeira que, segundo a religiosidade, fazem referência à simplicidade da vida de Jesus Cristo. Nesse sentido, o surgimento da aldeia encontra-se ligado não apenas às demandas de moradia enfrentadas por alguns indivíduos, mas aos próprios projetos desenvolvidos em torno dos agenciamentos da cultura. De modo mais específico, a construção dos novos funcos se orientou por uma perspectiva segundo a qual seria possível materializar os aspectos comunitários que municiam os discursos de patrimonialização. Como proposto nos projetos dos Rabelados, o objetivo dessas construções consiste em valorizar o patrimônio através do habitat, porque através das estruturas físicas das moradias seria possível 'conservar a consciência viva' do que significa o 'viver numa comunidade rabelada'.

Se essas construções traduzem parte da dimensão material da cultura dos Rabelados, sendo então compreendidas como elemento tangível do patrimônio cultural do grupo, sua concepção tornou-se fundamental para o desenvolvimento dos projetos turísticos. É a partir da estrutura física baseada nos funcos que se torna possível conceber um espaço a ser visitado, no qual os elementos culturais podem ser 'consumidos' não apenas em seus aspectos materiais (a arquitetura tradicional, a materialidade da vida rural, etc.), mas em seus sentidos 'vividos', nos termos de um 'consumo' de atividades cotidianas próprias de uma coletividade específica. 
Atualmente, todas as benfeitorias realizadas na aldeia visam ampliar a possibilidade de recepção de turistas. Em conjunto com os funcos foram edificadas outras construções, sendo elas o atelier dos artistas Rabelados, que comporta uma oficina e uma loja onde são expostas e comercializadas as pinturas e cerâmicas, bem como a sede da Associação, que contém estruturas destinadas não apenas aos projetos sociais e oficinas artísticas em desenvolvimento, mas ainda cômodos adaptados à recepção de visitantes, como quartos, cozinhas e banheiros. Dentre os projetos de ampliação dessas estruturas constam propostas de edificação do museu dos Rabelados, além de um restaurante que, segundo a expectativa dos membros da Associação, deve atender as demandas turísticas relativas à 'gastronomia tradicional'.

Em geral, as visitas à aldeia são guiadas pelos mediadores, obedecendo a um roteiro básico que explora diferentes pontos da estrutura física e geográfica disponível, incluindo-se visitações aos funcos, refeições coletivas, apresentações artísticas e passeios pelas áreas montanhosas que contornam a região do Espinho Branco. Nesse roteiro, os funcos habitados pelos indivíduos mais antigos configuram parada obrigatória, mais ainda no caso dos narradores talentosos e sempre disponíveis para recuperar a história de resistência ao colonialismo ou explicar os fundamentos do pensamento religioso dos Rabelados. É possivel detectar um comprometimento total dos membros da aldeia com a recepção aos visitantes. Desse modo, a entrada nos funcos e a participação direta no cotidiano dos moradores são possibilidades não apenas permitidas, mas incentivadas. É através desse tipo de intercâmbio que se propõe o 'consumo' da cultura local, sendo viabilizado ao turista o contato com a lógica reciprocitária (a alimentação compartilhada nos funcos ou o artesanato ofertado como dádiva), com a culinária típica (o consumo da cachupa e do xerém) e com a produção artística (a pintura em tela, a confecção da cerâmica e das peças em palha).

O fluxo de turistas é irregular e depende de esforços obstinados por parte dos mediadores. Na maior parte dos casos, aqueles que 
chegam à localidade são levados em grupos organizados através dos contatos prévios estabelecidos pelos ativistas. Em outras situações, parcerias com agências de turismo internacional têm promovido um incremento relativo do número de visitantes, caso da agência francesa Nômade, que remete ao Espinho Branco grupos de turistas em três ou quatro oportunidades por ano. Os recursos financeiros despendidos dependem do tempo que o visitante permanece na aldeia, sendo quase sempre calculados a partir da quantidade de diárias e refeições servidas na cozinha da Associação. Somados ao expediente advindo da comercialização da produção artística e das parcerias estabelecidas com o campo institucional, os recursos provenientes do turismo são gerenciados pela Associação dos Rabelados e reinvestidos nos projetos sob desenvolvimento na comunidade, com centralidade para aqueles que permitirão a ampliação da infraestrutura patrimonial e turística.

\section{Sistematizando as impressões etnográficas: da cultura como recurso aos empreendimentos patrimoniais e turísticos}

Considera-se que a compreensão dos agenciamentos que envolvem comunidades como a dos Rabelados deva partir de uma observação atenta sobre as formas contemporâneas através das quais a concepção de cultura adquiriu uma conotação recursiva, numa relação em que as articulações entre os discursos do patrimônio e o turismo demonstram-se centrais.

Autores como George Yúdice (2006) têm chamado a atenção para os diferentes processos através dos quais a categoria cultura tem sido percebida como um recurso para investimentos ou contestações, atuando como 'ferramenta' para uma variedade de propósitos sócio-políticos e econômicos. Trata-se de uma realidade em que o gerenciamento, conservação, distribuição e investimento em cultura tornaram-se prioridades na agenda de instituições públicas e privadas. Destacam-se aqui as múltiplas flutuações do conceito nessas agendas, cujos exemplos podem ser percebidos nas diferentes 
modalidades de seu acionamento por instituições como a UNESCO, que das concepções restritas e adotadas no surgimento da instituição (a versão romântica na qual cultura relaciona-se com o acúmulo de saberes compartilhados por um povo ou nação) passou a acolher as definições politizadas e desenvolvimentistas recentemente conferidas ao termo (Pitombo 2007).

Nessas definições, por um lado, observa-se a ideia de que a diversidade cultural é relevante para propósitos de ampliação da cidadania, especialmente no que se refere às demandas por reconhecimento. Decerto, trata-se aqui de concepções tributárias aos processos de fragmentação da sociedade civil, ocorridos em meio ao deslocamento do eixo do trabalho como principal fonte de organização das reivindicações coletivas, realidade na qual a possibilidade de 'se fazer representar culturalmente' tornou-se uma das principais características da democracia contemporânea (Kymlicka 1996; Melucci 2001). Por outra via, solidifica-se a noção de que a diversidade cultural apresenta-se como fundamental para o desenvolvimento social e econômico (Bayardo 2007). Como propõe Burity (2007), a aproximação entre a ideia de desenvolvimento e a noção de cultura se consolidou junto ao avanço das tendências neoliberais posteriores à década de 1990, que somadas ao crescimento das indústrias criativas fomentaram percepções sobre o potencial de rentabilidade contido nas manifestações dos grupos periféricos, com especial atenção para as propostas de comercialização de seus artefatos culturais. Dito de outro modo, emergiram concepções através das quais a cultura deixou de representar obstáculo ao crescimento econômico, sendo então encarada como atrativo a ser 'negociado' em proveito das políticas de desenvolvimento e integração social ${ }^{10}$.

Essas expectativas se ampliaram no âmbito das políticas direcionadas ao empoderamento dos grupos marginalizados, para os quais a cultura e os valores transformaram-se não apenas em objetos que organizam a luta pelo reconhecimento (Honneth 2003), mas num rentável capital a ser administrado. Como demonstram algumas análises, 
essa última perspectiva sinaliza um contexto em que as lógicas de ação dos grupos subalternos podem por vezes se deslocar das arenas políticas para os domínios do mercado empresarial. Trata-se de um movimento em que as construções identitárias articularam-se ao capital financeiro, desvelando-se uma tendência de incorporação à modernidade que demanda a gestão dos ativos simbólicos de que cada grupo dispõe. Segundo Jean e John Comaroff (2009), tal tendência desenvolve-se através da conciliação de diversos fatores, tais como a emergência das políticas de identidade na atualidade global, a disseminação de uma cultura do empreendedorismo típica dos contextos neoliberais, ou ainda a ampliação da judicialização das relações sociais e das políticas de propriedade intelectual. Nesse viés, os processos de comodificação da cultura dos grupos marginalizados têm substituído a venda de sua mão-de-obra através de relações em que os artefatos culturais podem ser geridos, transformados em propriedade e comercializados nos mercados locais, nacionais e transnacionais. Trata-se do advento do cultural branding: o fenômeno das 'etnomercadorias' e da 'identidade constituída como pessoa jurídica' (Comaroff $\&$ Comaroff 2009).

Ocorre que essas iniciativas têm sido realizadas prioritariamente através dos discursos do patrimônio (Bayardo 2007) e das negociações em torno do turismo cultural (Talavera 2003). De modo reiterado, a centralidade desses projetos, no âmbito dos agenciamentos da cultura, relaciona-se com uma ideia de complementaridade segundo a qual o patrimônio se apresenta como atrativo turístico na mesma razão em que o turismo permite a conservação patrimonial, cada esfera de ação sendo compreendida como propícia para o atendimento das demandas de reconhecimento identitário e empoderamento econômico. É em decorrência dessas expectativas que as agendas políticas internacionais passaram a comportar não apenas um acionamento recursivo da categoria cultura, mas também aqueles instrumentos básicos que supostamente possuem a capacidade de gerar os resultados esperados: as políticas do patrimônio e os empreendimentos turísticos. 
Conforme Yúdice (2006), essas estratégias se difundem por diferentes contextos em decorrência de uma divisão internacional do trabalho cultural na atualidade global, o que gerou a proliferação de redes de organismos estabelecidos em níveis nacionais e internacionais com os quais os atores sociais necessitam negociar. Seja em razão das negociações estabelecidas em rede com essas corporações (Yúdice 2006), seja através do protagonismo dos mediadores culturais inseridos nessas redes (Agier 2001), os agenciamentos em torno do patrimônio e do turismo tornaram-se estratégias básicas para o empoderamento de atores periféricos em diversas regiões do globo.

A recuperação desse panorama permite uma compreensão parcial sobre o modo como certos agenciamentos se desenvolvem atualmente em comunidades africanas rurais como a do Espinho Branco. Empenhados em negociações com agências públicas e privadas estabelecidas nos níveis nacionais e transnacionais, e em contato com ativistas de ampla circulação por essas instituições, os Rabelados se inserem numa configuração política através da qual a negociação de sua cultura se tornou estratégia imprescindível na mediação de suas aproximações com a modernidade e com o universo urbano, seja no que se relaciona com suas expectativas de reconhecimento, seja no que concerne às suas demandas de empoderamento econômico.

\section{Problematizando a comodificação das culturas: negociações da identidade e da autenticidade}

De acordo com Tomassi (2013), se é correto afirmar que os agenciamentos culturais contemporâneos propiciam um espaço mais amplo na configuração dos canais de acesso a recursos e processos de reconhecimento para os grupos socialmente marginalizados, tal realidade também desperta dúvidas sobre possíveis cooptações políticas implicadas na aproximação de coletividades periféricas com as lógicas economicistas do mercado (Burity 2007). Cabe ressaltar que a disponibilização desses recursos ou dos espaços para novas políticas de representação demanda, na maior parte dos casos, um enquadramento a modelos técnicos 
e mercadológicos que podem desvalorizar os agentes envolvidos e suas culturas. Entretanto, considerando que os possíveis custos dessas ações se demonstram contingenciais (Comaroff \& Comaroff 2009), uma avaliação específica do caso dos Rabelados revela-se apropriada para a compreensão das modalidades contemporâneas de agenciamento cultural. Conforme antecipado mais acima, no universo empírico aqui enfocado as complexidades que se destacaram no contexto dos empreendimentos patrimoniais e turísticos puderam ser refletidas a partir das tematizações relativas às negociações identitárias e à autenticidade.

A problemática das negociações de identidade não é novidade nas reflexões sobre a comodificação das culturas, mais ainda no que se refere ao turismo cultural. Foram diversas as análises que chamaram a atenção para os efeitos perniciosos que a atividade turística pode representar para os processos de identificação nas comunidades envolvidas, ressaltando-se aqui os condicionamentos que decorrem das demandas de mercado: a simplificação dos códigos culturais, a exotização da diferença, o enquadramento das representações e práticas em estereótipos. Essas problemáticas têm sido detectadas em profusão na expansão do turismo cultural, em relações nas quais o próprio continente africano tem revelado exemplos dramáticos. A esse respeito, são sintomáticas as análises de John Akama (2002) sobre os impactos do turismo entre os Maasai no Kenya, constatando-se representações que reforçam visões etnocêntricas sobre o 'caráter' supostamente 'selvagem' das culturas africanas. Alguns exemplos relatados por Jean e John Comaroff (2009) corroboram com essas análises, fazendo referência às simplificações identitárias em aldeias de turismo cultural na África do Sul, nas quais se detectam abstrações que desconsideram conflitos, diferenças e divisões internas de grupos tão distintos como Zulus, Tsuanas e San. É desnecessário ampliar os exemplos para pressupor que muitas dessas situações reforçam preconceitos e estigmas, enfraquecendo as relações que envolvem a subjetividade cultural.

Contudo, no caso dos Rabelados, as realidades que emergiram na prática etnográfica permitem avaliar relações que se apresentam como 
positivas para o âmbito das negociações da identidade. Decerto, deve-se considerar aqui o fato de estarmos tratando de agenciamentos ainda restritos às estratégias de grupos periféricos, observando-se que a ausência de uma efetiva lógica de mercado concorre para um quadro em que a adaptação a esquemas de percepção simplificados encontrese distante. Ao contrário, o que se constata nas realidades disponíveis no Espinho Branco corresponde à emergência de um espaço narrativo no qual performances identitárias endereçadas aos visitantes possibilitam um reforço das singularidades e da subjetividade cultural. Assim se observam as longas narrativas de um senhor Rabelado com mais de 80 anos que descreve de modo pormenorizado os elementos de sua religiosidade diante de visitantes atenciosos, num cenário em que as 'ameaças' da modernidade secular, advindas do inevitável contato com a realidade exterior à aldeia, podem ser compensadas numa performance que mantém viva a memória coletiva e religiosa do grupo, ainda que em articulações repletas de ressignificações. $\bigcirc$ mesmo vale para as narrativas de um artesão de peças em palha que recebe cotidianamente em seu Funco visitantes interessados nos relatos sobre a resistência de seus antepassados em relação às políticas colonialistas. Conforme me propôs esse agente, trata-se de uma oportunidade especial, até então distante dos Rabelados, que permite não apenas recuperar a trajetória do grupo, mas descrevê-la conforme a percepção dos próprios indivíduos da aldeia. Em outras palavras, constatam-se espaços propícios para um exercício narrativo que oportuniza mais que o reforço da memória coletiva rabelada, mas ainda um ambiente de produção discursiva configurado na fala dos próprios Rabelados. Assim, subverte-se a relação de poder que outrora se encerava em discursos articulados pelos representantes oficiais do Estado cabo-verdiano, até bem pouco tempo os únicos produtores de sentido sobre as realidades que envolvem a historicidade daqueles coletivos.

É provavelmente a partir dessas perspectivas que se torna compreensível a recorrente ideia entre os Rabelados de que os projetos desenvolvidos na aldeia se demonstram exitosos, numa avaliação com- 
partilhada pela quase totalidade do grupo. Como se diz comumente entre os moradores do Espinho Branco, se os expedientes oriundos da produção artística e do turismo ainda não resolveram os problemas decorrentes da escassez de recursos e da inexistência de uma política pública reparadora e direcionada aos Rabelados, a emergência daquelas ações estratégicas tem promovido uma mudança decisiva na forma pela qual esses coletivos são vistos pela sociedade cabo-verdiana. Como me refere um pintor da associação Rabelarte, a partir daqueles empreendimentos, o grupo passou a ser valorizado e respeitado por 'gente da terra' e 'gente de fora', sendo reconhecido até mesmo no 'além mar' - numa referência direta à presença da arte dos Rabelados em vernissages organizadas no continente europeu. $\mathrm{O}$ que parece importante é que essa percepção acerca do reconhecimento não se demonstra gratuita ou alienada numa visão descontextualizada, estando diretamente ligada a uma lógica de reforço das singularidades, a qual se baseia em performances narrativas que tanto recuperam a memória coletiva do grupo quanto propiciam novos meios para uma constante recriação da subjetividade cultural.

O que se está propondo aqui é que as atividades turísticas realizadas em baixa escala podem, por vezes, propiciar uma espécie de 'palco' para que determinados agentes lacem mão de performances e dramatizações rituais que os permitem falar, atuar, recriar ou refletir sobre a própria existência, assim reafirmando suas pertenças e singularidades através de espaços narrativos que até então se encontravam restritos aos regimes de representação oficiais. Nesses processos, é justamente a presença de visitantes que possibilita o surgimento de um exterior constitutivo através do qual a identidade se configura e se reforça (Hall 2000). É válido retomar aqui a consideração de Fredrik Barth (1988) de que a constituição dos grupos, como unidade significativa, só se mantém com base na interação dos elementos diacríticos que emergem da confrontação entre alteridades diversas. Assim, pode-se avaliar que estamos diante de um aspecto de potencial criativo dos processos de comodificação, observando-se novos modos de auto- 
constituição individual e coletiva que apesar da comercialização da identidade acabam reafirmando as consciências coletivas (Comaroff $\&$ Comaroff 2009). Desse modo, se a identidade e a cultura rabelada transformam-se em 'bens' a serem 'negociados' e 'consumidos', tratase antes de bens que operam como suportes rituais de diferenciação e marcação social (Douglas \& Isherwood 2006).

A referência a esses processos de recriação, ressignificação e atualização da memória coletiva através de performances destinadas aos turistas leva-nos à outra dimensão relevante da problemática da comodificação. Presente desde os debates da Escola de Frankfurt, a questão da autenticidade encontra-se no cerne das agendas de pesquisa destinadas a avaliar os agenciamentos que operam com base na mercantilização dos artefatos culturais, cujos efeitos foram por muito tempo interpretados nos termos da capacidade que a produção mercadológica da cultura possui para retirar desses objetos sua condição fundamental de existência, seu valor curativo e aurático (Adorno 1975). Assim, se o autêntico se define pelo vínculo inexorável com a experiência concreta dos indivíduos (Sapir 1924), a inautenticidade se liga a imposições externas, artificialmente concebidas e desconexas da realidade cultural.

Seriam esses os fatores que, em princípio, se realizam nos agenciamentos sintonizados com mercado ou com o campo político, que para satisfazer as demandas oriundas dessas esferas recriam manifestações específicas segundo padrões e esquemas simplificados. Nessa perspectiva, tanto os empreendimentos de turismo cultural quanto os processos de patrimonialização seriam eficazes nesses esquematismos, não raramente promovendo-se uma redução semântica nas manifestações das coletividades envolvidas (Trajano 2012). O problema dessas operações para os membros de comunidades marginalizadas relaciona-se não apenas com a desvalorização de suas formas de vida características, mas, sobretudo, com a imposição de sistemas sociais exteriores a suas estruturas de reprodução, os quais são impostos justamente em razão das reduções semânticas operacionaliza- 
das em favor da expansão da lógica de mercado capitalista e hegemônica (Canclini 1983).

Entretanto, assim como no caso das negociações de identidade, as realidades disponíveis na aldeia do Espinho Branco nos permitem uma visão mais relativa desses processos, concebendo-se fatores positivos no que se refere às questões da autenticidade e da redução semântica dos objetos da cultura. Aqui é possível recorrer novamente à ideia de geração de um espaço narrativo e performático benéfico para os agentes envolvidos. Um exemplo das negociações que envolvem a religiosidade dos Rabelados demonstra-se exemplar a esse respeito. De fato, as narrativas sobre a religião expostas aos turistas estão muito distantes dos antigos ciclos rituais existentes na aldeia, caso das leituras bíblicas coletivas que até bem pouco tempo eram freqüentes na liturgia dos Rabelados. Como se diz comumente no Espinho Branco, hoje não há mais necessidade dessas práticas porque a maioria dos indivíduos tem acesso às escrituras sagradas, condição que decorre tanto dos processos de alfabetização quanto da interferência dos valores seculares. Contudo, o que se observa na figura dessas narrações é a possibilidade de um trabalho de mediação entre um presente de mudanças inevitáveis e um passado no qual a ritualização do sagrado ainda era decisiva, o que é favorecido pelo surgimento das novas performances rituais (profanas) que geram condições de reflexão sobre as próprias transformações em curso. Assim, a cada narrativa enunciada aos visitantes da aldeia, percebe-se que os Rabelados refletem sobre 'como se era', 'como se vivia' ou 'como se faziam as coisas' e o 'como se passou a ser, viver e fazer' (em termos religiosos, políticos ou familiares).

O acionamento dos discursos do patrimônio também configura exemplo pertinente a esse respeito. Como me informa uma artista da aldeia, o que se pretende com o museu ou com as pinturas consiste na retratação daquilo que 'não pode ser esquecido', sem que se obstruam os olhares para 'o que vem de fora', ou seja, 'as novidades'. Observa-se aqui de uma visão que traduz com perspicácia a noção do patrimônio 
como categoria de pensamento (Gonçalves 2005), cujas funções simbólicas atuam na mediação entre espaços, estados e temporalidades diversas, relacionando perspectivas distintas como passado e presente, rural e urbano, tradição e modernidade. Em que pese o fato dos agenciamentos turísticos e patrimoniais operarem uma efetiva redução semântica nas manifestações culturais dos Rabelados, parece factível avaliar que esses mesmos agenciamentos, considerados nos termos de performances narrativas, engendram meios de reflexão sobre as realidades e mudanças experimentadas na aldeia do Espinho Branco em sua situação contemporânea. Dito de outro modo, os discursos do patrimônio e os empreendimentos turísticos favoreceram o surgimento de determinados mecanismos de mediação, os quais geram reflexividade e proporcionam aos Rabelados novas formas para compreender as experiências sociais das quais fazem parte.

Poderíamos aqui recorrer a Walter Benjamim (1985) e suas análises sobre a reprodutibilidade da obra de arte para se pensar na emergência de meios técnicos que, mais do que promover a destruição aurática de expressões culturais específicas através das lógicas de reprodução (e comodificação), geram formas renovadas de percepção coletiva sobre os objetos da cultura. No caso dos Rabelados, esses meios sugerem modos alternativos pelos quais o grupo percebe sua cultura em interface com alteridades diversas, ainda fomentando reflexões sobre as contradições que envolvem a própria existência rabelada.

\section{Conclusões}

O contato com as formas contemporâneas de agenciamento da cultura não se limita à geração de questionamentos antropológicos instigantes. Mais do que isso, a observação de paisagens etnográficas como aquelas analisadas neste texto podem nos apresentar situações complexas que demandam reflexão epistemológica. Por um lado, é difícil estabelecer contato com agentes otimistas em relação às expectativas de empoderamento econômico e reconhecimento identitário através da mercantilização de sua cultura e não ser tentado a consid- 
erar tais estratégias como soluções plenamente viáveis em contextos de marginalidade social. Por outra via, a aproximação com realidades que abarcam processos de comodificação cultural através do turismo ou do patrimônio e todos os tensionamentos que daí decorrem podem nos incentivar a adotar uma visão pessimista e ao mesmo tempo romântica, assim incorrendo-se nos equívocos das análises baseadas na ideia da descontinuidade cultural. As alternativas a essas inquietações parecem não ultrapassar algumas considerações breves presentes na teoria cultural contemporânea. Por um lado, não é possível conceber os artefatos da cultura como objetos inalienáveis e apartados das relações de mercado. Por outro, a avaliação dos possíveis impactos dessas formas de agenciamento na experiência concreta dos atores sociais não deve desconsiderar o caráter contingente desses processos.

Ressaltando essa dimensão contingente e situacional, nesse artigo argumentei que os agenciamentos observados numa comunidade dos Rabelados de Cabo Verde podem ser considerados como positivos, sobretudo no que se refere às negociações da identidade e à problemática da autenticidade cultural. De modo independente a seus propósitos originais, relacionados às estratégias de reconhecimento identitário e empoderamento econômico, é possível avaliar que, de um lado, a implementação do turismo cultural em baixa escala pode favorecer a emergência de um espaço performático e narrativo através do qual se realiza o reforço da subjetividade cultural. Noutro enfoque, é também através desse espaço performático ritualizado no cotidiano da aldeia, bem como do acionamento de categorias como patrimônio, que emergem possibilidades de reflexão sobre as relações entre o passado e o presente, a tradição e a modernidade, avaliando-se que os agenciamentos culturais observados nesses contextos atuam numa espécie de mediação das contradições que se estabelecem na aproximação desses coletivos com a modernidade urbana e capitalista. Assim, se é possível afirmar que aquelas modalidades de política cultural têm acelerado a abertura desses grupos em relação à sociedade envolvente, é também necessário referir que não se trata apenas de antecipar àquela aproxi- 
mação, mas de processos que permitem a mediação simbólica de conexões que há muito se demonstram inevitáveis.

Minhas ponderações abordam tópicos restritos do fenômeno $R a$ belados. A observação dos possíveis impactos dos agenciamentos culturais referidos na experiência do grupo demanda a inclusão de novas categorias de análise, o que pode ampliar as reflexões aqui expostas. Assim, torna-se necessário relacionar as complexidades que envolvem as negociações estabelecidas com as agências que eventualmente abalizam parcerias institucionais com as comunidades, desse modo investigando-se as condições para o protagonismo dos agentes envolvidos nesses processos. Por outra via, com base na constatação de que as ações existentes entre os Rabelados ainda se encontram numa dimensão propositiva e distante de grandes investimentos do capital privado ou da gestão estatal, seria interessante um olhar comparativo com outros empreendimentos turísticos e patrimoniais em comunidades similares e com níveis de interação mercadológica e política distintos. Assim poderiam ser viabilizadas reflexões sobre os limites que o enquadramento a modelos de mercado ou os condicionamentos políticos impõem sobre os agenciamentos investigados. Tais questionamentos parecem compor uma interessante agenda de pesquisa, cuja delimitação empírica pode ir além das comunidades rurais e periféricas, avaliando-se múltiplas formas de negociação cultural entre coletividades distintas e seus diferentes níveis de envolvimento com os campos político e econômico.

Importa ainda referir que o enfoque pelo qual me aproximo dos Rabelados não ignora outras dimensões de sua historicidade, como a religiosidade ou as tensões endógenas do grupo relacionadas à aproximação com a sociedade envolvente, com o capitalismo e com a modernidade urbana. Ao considerar a centralidade dos empreendimentos patrimoniais e turísticos na experiência contemporânea desses coletivos estou apenas propondo que aquelas outras dimensões já não podem ser compreendidas sem uma análise dos agenciamentos que se estabelecem em torno da concepção de cultura. 


\section{Notas:}

1 Trata-se das atividades de pesquisa realizadas no âmbito do Laboratório de Políticas Culturais e Ambientais do Brasil - LAPCAB, grupo de pesquisa vinculado ao Programa de Pós-Graduação em Ciências Sociais da Universidade do Vale do Rio dos Sinos - UNISINOS/RS.

2 Além dos Rabelados, essas investigações se referem aos agenciamentos e políticas da cultura na sociedade cabo-verdiana, tendo como contextos empíricos os processos de patrimonialização da Cidade Velha (Ribeira Grande) e a realização da Atlantic Music Expo - AME (Praia), ambas na ilha de Santiago, bem como as atividades do grupo carnavalesco Mandingas (Mindelo), na ilha de São Vicente.

3 Espinho Branco corresponde a uma região, ou 'zona', localizada ao norte da Ilha de Santiago.

4 Trata-se da região que comporta o maior número de indivíduos auto identificados como Rabelados. A aldeia do Espinho Branco também concentra a maior parte dos projetos que atualmente visam à integração social das comunidades Rabeladas.

5 Os dados que municiam a reflexão são oriundos de observações etnográficas realizadas na aldeia do Espinho Branco, bem como de entrevistas semiestruturadas aplicadas aos membros da comunidade e aos ativistas culturais envolvidos com os agenciamentos observados. Tais inserções se deram no primeiro semestre de 2015. Também foram analisados documentos relativos a projetos de captação de recursos destinados aos empreendimentos patrimoniais e turísticos disponíveis. Contatos informais e a distância com atores deste contexto, bem como o acompanhamento dos agenciamentos da aldeia do Espinho Branco perduraram até o final de 2018.

6 No âmbito das questões identitárias são favorecidas inferências sobre os custos simbólicos do processo, avaliando-se a lógica discursiva dos regimes de representação em negociação (Hall 2010). Aqui se torna possível a visualização das tensões representacionais em jogo no campo dos agenciamentos da cultura. Por sua vez, a autenticidade apresenta-se como categoria que permite avaliar as reduções semânticas dos artefatos da cultura em contextos de patrimonialização e turismo. Uma vez que essas reduções podem atuar na subjugação das culturas rurais/periféricas em relação à lógica hegemônica capitalista (Canclini 1983), trata-se de um viés que permite avaliar possíveis cooptações políticas e mercadológicas presentes naqueles agenciamentos (emergência de novas relações de dependência, etc.).

7 Essas categorias estão presentes em inúmeras correspondências de agentes do Estado colonial português do período, conforme os anexos apresentados na obra de Monteiro (1974).

8 Caso dos movimentos profético-messiânicos encontrados em outros países do continente africano, como aqueles estudados por Balandier (1970).

9 Essas parcerias incluem instituições como a Organização Mundial da Saúde (OMS), o Ministério da Educação e o Ministério da Justiça de Cabo Verde, ou ainda a empresa privada de telefonia CV Telecom.

10 Segundo Burity (2007), a vinculação entre cultura e desenvolvimento tem sido formatada desde as políticas desenvolvimentistas do pós-guerra. Se nesse primeiro 
momento tais perspectivas ainda se encontravam apartadas devido à percepção de que as culturas locais poderiam representar impedimentos para um desenvolvimento integrado em termos globais, os fracassos dos projetos desenvolvimentistas nos países periféricos na década de 1980 tornaram claro que aquelas políticas demandavam uma articulação concreta entre os projetos econômicos e as representações culturais específicas.

\section{Referências:}

ADORNO, T. 1975. “A Indústria Cultural”. In COHN, G. (ed.): Comunicação e Indústria Cultural, pp. 287-295. São Paulo: Cia. Editorial Nacional.

AGIER, M. 2001. “Distúrbios identitários em templos de globalização”. Mana, 7(2):7-33.

AKAMA, J. 2002. "The creation of the Maasai image and tourism development in Kenya”. In AKAMA, J. \& STERRY, P. (eds.): Cultural Tourism in Africa: strategies for the new millennium, pp. 43-54. Arnhem: Association for Tourism and Leisure Education.

ASCHER, F. 2011. Os Rabelados de Cabo Verde: história de uma revolta. Paris: L'Harmattan.

AZARYA, V. 2001. "Globalization and international tourism in developing countries: marginality as a commercial commodity". Current Sociology, 6(52):994-967.

BALANDIER, G. 1976. Antropológicas. São Paulo: Editora Cultrix. . 1970. The sociology of Black África: social dynamics in central África. Londres: Andre Deutsch Limited.

BARTH, F. 1998. "Grupos étnicos e suas fronteiras”. In POUTIGNAT, P. \&STRAIFF-FENART, J. (eds.). Teorias da etnicidade, pp. 187-227. São Paulo: Editora da UNESP.

BAYARDO, R. 2007. "Cultura y desarrollo: nuevos rumbos y más de lo mismo?” In NUSSBAUMER, G. (ed.). Teorias e politicas da cultura: visões multidisciplinares, pp. 67-94. Salvador: EDUFBA.

BENJAMIN, W. 1985. "A obra de arte na era de sua reprodutibilidade técnica”. In BENJAMIN, W. (ed.): Magia e técnica, arte e política: ensaios sobre literatura e história da cultura, pp. 165-196. São Paulo: Brasiliense.

BONIFACE, P. \& FOWLER, P. 1993. Heritage and tourism in 'The Global Village'. Londres: Routledge.

BURITY, J. 2007. "Cultura e desenvolvimento”. In NUSSBAUMER, G. (Org.). Teorias e políticas da cultura: visões multidisciplinares, pp. 51-66. Salvador: EDUFBA. 
CANCLINI, N. 2013. Culturas híbridas: estratégias para entrar e sair da modernidade. São Paulo: Editora da UNESP.

. 1983. As culturas populares no capitalismo. São Paulo: Brasiliense.

COMAROFF, J. \& COMAROFF, J. 2009. Etnicidad S.A. Madrid: Katz.

DANIEL, Y. 1996. "Tourism dance performances: authenticity and creativity". Annals of Tourism Research, 23(4):780-797.

DIAS, R. 2006. Turismo e patrimônio cultural: recursos que acompanham o crescimento das cidades. São Paulo: Saraiva.

DOUGLAS, M. \& ISHERWOOD, B. 2006. O mundo dos bens: para uma antropologia do consumo. Rio de Janeiro: EdUFRJ.

GONCALVES, M. L. 2009. "Rabelados no Bacio e no Espinho Branco: pontes e portas na (re)formulação identitária do grupo”. In LUCAS, M. E. \& SILVA, S. (eds.): Ensaios etnográficos na ilha de Santiago de Cabo Verde: processos identitários na contemporaneidade, pp. 229-262. Porto Alegre: Editora da UFRGS.

GONÇALVES, J. 2005. "Ressonância, materialidade e subjetividade: as culturas como patrimônios". Horizontes Antropológicos, 11(23):15-36.

HALL, S. 2010. "Identidad y representación". In HALL, S. (ed.): Sin garantias: trayectorias y problemáticas en estudios culturales, pp. 337-482. Popayán/ Colômbia: Envión Editores.

2000. "Quem precisa de identidade?". In SILVA, T. (ed.): Identidade e Diferença. A perspectiva dos Estudos Culturais, pp. 103-133. Petrópolis: Vozes.

HONNETH, A. 2003. Luta por reconhecimento: a gramática moral dos conflitos sociais. São Paulo: Ed 34.

KYMLICKA, W. 1996. Ciudadanía Multicultural: una teoría liberal de los derechos de las minorias. Barcelona: Paidos.

MARTÍN, E. 2009. "From Popular Religion to Practices of Sacralization: approaches for a conceptual discussion". Social Compass, 56(2):273-285.

MELUCCI, A. 2001. A Invenção do Presente: movimentos sociais nas sociedades complexas. Petrópolis: Vozes.

MONTEIRO, J. 1974. Os Rabelados da Ilha de Santiago, de Cabo Verde: história de uma revolta. Praia: Centro de Estudos de Cabo Verde, Sociedade Industrial Gráfica.

PITOMBO, M. 2007. "Entre o universal e o heterogêneo: uma leitura do conceito de cultura na UNESCO". In NUSSBAUMER, G. (ed.): Teorias e políticas da cultura: visões multidisciplinares, pp. 115-138. Salvador: EDUFBA.

SANTOS, F. L. 2009. "Construção Patrimonial da Cidade Velha: usos políticos, turísticos e identitários". In LUCAS, M. E. \& SILVA, S. (eds.): Ensaios etnográficos na ilha de Santiago de Cabo Verde: processos identitários na contemporaneidade, pp. 25-73. Porto Alegre: Editora da UFRGS.

SAPIR, E. 1924. "Culture: genuine and spurious". American Journal of Sociology, 29(4):401-429. 
TALAVERA, A. 2003. "Turismo cultural, culturas turísticas". Horizontes Antropológicos, 9(20):31-57.

TOMASSI, L. 2013. "Culturas de periferia: entre o mercado, os dispositivos de gestão e o agir político". Política e Sociedade, 12(23):11-34.

TRAJANO, W. 2012. "Patrimonialização dos artefatos culturais e a redução dos sentidos”. In SANSONE, L. (ed.): Memórias da África: patrimônios, museus e politicas das identidades, pp. 11-40. Salvador: EDUFBA.

YÚDICE, G. 2006. A conveniência da cultura: usos da cultura na era global. Belo Horizonte: Editora UFMG.

\begin{abstract}
The Rabelados consist of rural communities originating in the resistance to colonial power in Cape Verde, which have developed partially isolated from the state since the 1940s. Recently, however, initiatives undertaken by cultural mediators aim at the inclusion of these collectives into the surrounding society and, in these purposes, patrimonialization policies and cultural tourism are presented as main instruments. Coming from these realities, this article discusses the complexities surrounding these agencies. On the one hand, it seeks to characterize the ways in which the agencies around culture have become central in the contemporary world; on the other hand, it evaluates the most apparent results of these initiatives in the case of Rabelados, with special attention to the issues of identity negotiations and authenticity.
\end{abstract}

Keywords: Patrimonialization policies, Cultural tourism, Identities, Authenticities.

Recebido em junho de 2020. Aprovado em dezembro de 2020. 